'Centro UC Investigación en Oncología (CITO). ${ }^{2}$ Departamento de Hematología-Oncología, Escuela de Medicina, Pontificia Universidad Católica de Chile.

Fuente de apoyo financiero: Fondecyt\#15130011 Fondecyt\#1111014y Fondef\#D0911137

Recibido el 22 de junio de 2012, aceptado el 26 de diciembre de 2012

Correspondencia a: Dr. Alejandro Corvalán R. Centro UC de Investigación en Oncología (CITO) Pontificia Universidad Católica de Chile. Portugal 61, Santiago 8330074 Chile.

Teléfono: 56(2) 354-8289

Fax: 56(2) 6332544

E-mail: corvalan@med. puc.cl

\section{Bases epigenéticas del cáncer gástrico: oportunidades para la búsqueda de nuevos biomarcadores}

\author{
ALEJANDRO CORVALÁN R. ${ }^{1,2}$
}

Gastric cancer is the first cause of death for cancer in Chile. The recently identified genetic alterations in these tumors have not yielded new biomarkers for the disease. Epigenetics or the study of reversible genomic changes that do not affect protein codifying DNA sequences but cause phenotypic disturbances, is identifying new cancer biomarkers. Specifically, the loss of expression caused by the covalent link of a methyl group to carbon 5 of cytosine (DNA hypermethylation) is extensively evaluated. Performing an epigenetic evaluation of 24 genes, we have identified eight genes associated to the aggressive signet ring cell type gastric cancer, the association between APC hypermethylation and worse prognosis and BRCA1 hypermethylation association with early onset of gastric cancer. The most interesting findings are the hypermethylation of Reprimo gene in plasma as a population biomarker and the tissue over expression of 773 gene (as a consequence of hypomethylation) as a high risk indicator of progression to gastric cancer. All these findings are indicating an important role of epigenetics in the pathogenesis and early detection of gastric cancer.

(Rev Med Chile 2013; 141: 1570-1577)

Key words: Biological markers; Epigenomics; Stomach neoplasms.

$\mathrm{E}$ 1 cáncer gástrico es la primera causa de muerte por enfermedades neoplásicas en Chile y la segunda en el mundo ${ }^{1,2}$. A pesar de los avances en el tratamiento y una disminución de sus lesiones precursoras ${ }^{3,4}$, recientes publicaciones sugieren un probable aumento de su mortalidad, particularmente en población joven ${ }^{5}$. Estas observaciones, en conjunto con proyecciones de la mortalidad global para los próximos 20 años, sugieren que el cáncer gástrico ocupará la décima causa global de muerte para la década del $2030^{6}$. El cáncer gástrico se puede clasificar según aspectos clínicos, endoscópicos o histológicos ${ }^{7-13}$. La clasificación más utilizada es la propuesta por Lauren ${ }^{13}$, la cual, según parámetros histológicos, define dos tipos de cáncer gástrico: el intestinal y el difuso. El primero se caracteriza por la formación de estructuras glandulares que semejan la mucosa colónica y que está precedida por una secuencia de lesiones muy bien caracterizadas por Correa y col. ${ }^{14,15}$. Por otra parte, el cáncer gástrico de tipo difuso, no forma estructuras histológicas y en consecuencia no tiene lesiones precursoras reconocidas ${ }^{16}$. Una particularidad importante de la clasificación de Lauren es que ha sido muy útil para estudiar el rol del ambiente, en particular en la variante intestinal ${ }^{15}$. En este sentido, las lesiones precancerosas han demostrado progresar de forma dinámica, desde la gastritis crónica superficial, gastritis crónica atrófica, metaplasia intestinal y finalmente displasia. Estos eventos constituyen las bases del "modelo humano de cáncer gástrico" postulado por Correa ${ }^{17}$. Una de las características fundamentales de este modelo es que junto con identificar una secuencia progresiva de lesiones, señala también la existencia de progresión/regresión de estas lesiones. 


\section{$\underline{\text { Bases moleculares del cáncer gástrico }}$}

Las bases moleculares del cáncer gástrico y sus lesiones precursoras comenzaron a identificarse con los reportes de la inactivación de genes supresores de tumores, como la proteína supresora tumoral $\mathrm{p} 53^{18} \mathrm{y}$ activación de oncogenes, como cerbB2 ${ }^{19-21}$. Posteriormente, un número creciente de genes han sido identificados ${ }^{22,23} \mathrm{y}$ algunos de ellos han sido descritos en las lesiones precancerosas ya mencionadas previamente ${ }^{24}$. Sin embargo, la frecuencia de alteraciones genéticas de cada uno de estos genes es muy baja y no permite construir un modelo molecular del cáncer gástrico. En este sentido, mutaciones en el gen E-caderina se han descrito asociadas al síndrome hereditario de cáncer gástrico difuso (HDGCS ${ }^{25-28}$. Sin embargo y en forma paradojal, en las formas no hereditarias del cáncer gástrico difuso, no se han demostrado alteraciones genéticas de E-caderina ${ }^{29,30}$. Por otra parte, se ha observado con mucha frecuencia la pérdida de heterocigosidad ( $\mathrm{LOH})$ y la inestabilidad de microsatélites (MSI) en cáncer gástrico $^{23,31,32}$. De modo similar, mutaciones en los genes de reparación del ADN, hMSH2 y hMLH1, responsables de la generación de LOH y MSI, no son frecuentes ${ }^{23,33}$. Tomadas en conjunto, estas observaciones sugieren que las alteraciones genéticas no explican por completo las bases moleculares del cáncer gástrico.

\section{Epigenética y cáncer gástrico}

La epigenética estudia los cambios reversibles $y$ heredables en el genoma de una célula que no afectan las secuencias del ADN codificantes para proteínas. Estos cambios reversibles a nivel del epigenotipo, junto con modificaciones en el genotipo e interacciones del medio ambiente, producirán finalmente modificaciones a nivel del fenotipo de una célula ${ }^{34}$. Esta nueva disciplina asigna un papel relevante a las secuencias del ADN no codificantes para proteínas y ha sido definida como la "materia negra del genoma" ${ }^{35}$. Los principales mecanismos de la epigenética son: i) la metilación del ADN (hipo e hipermetilación); ii) las modificaciones de histonas y remodelación de la estructura de la cromatina y iii) los microARNs. La metilación del ADN implica la adición covalente de un grupo metilo de la S-adenosilmetionina (SAM) en el car-

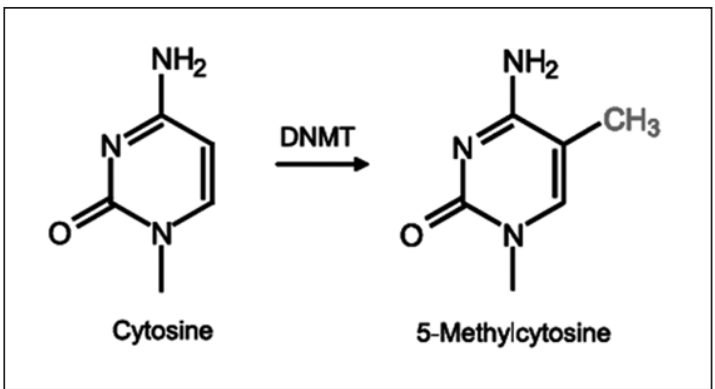

Figura 1. Metilación del ADN caracterizado por la incorporación de un grupo metilo (- $\mathrm{CH} 3$ ) en el carbono 5 del anillo de pirimidina de las citosinas. La incorporación de este grupo metilo es realizado por la enzima DiMetilTransferasa (DNMT). Tomado de Chen \& Riggs, J Biol Chem 2011; 286: 18347-53, con autorización.

bono 5 del anillo de citosina ${ }^{36}$. Esta modificación genera la base 5-metilcitosina $(5 \mathrm{mC})$ o "quinta base" (Figura 1). En mamíferos, $5 \mathrm{mC}$ se encuentra en aproximadamente $4 \%$ del ADN genómico, principalmente en dinucleótidos citosina-guanina $(\mathrm{CpG})$ y en regiones no codificantes como la región promotora de genes ${ }^{37}$. Por lo tanto, la metilación del ADN juega un papel importante en regular la expresión de genes asociados a desarrollo, diferenciación, envejecimiento y tumorigénesis. Una de las particularidades de esta regulación es su reversibilidad al tratamiento con la droga desmetilante 5-Azacytidina (5AzaC), lo cual abriría la posibilidad a nuevas estrategias terapéuticas. Por otro lado, la detección de la metilación del ADN, a través del proceso denominado "conversión por bisulfito" genera secuencias únicas, las que pueden ser detectadas con alta sensibilidad y a partir de cualquier tipo de muestras clínicas. Esta última característica convierte a la metilación del ADN en una potencial fuente de biomarcadores asociados a genes relacionados con la patogénesis del cáncer.

\section{Hipermetilación del ADN y cáncer gástrico}

La inactivación de genes supresores de tumores por metilación del ADN mejor documentada en cáncer gástrico es el silenciamiento de los genes de reparación hMLH1 y hMSH $2^{38}$. La inactivación de hMLH1 es responsable del desarrollo de la MSI. Esta inactivación conduce a mutaciones en secuencias repetitivas simple dentro de genes críticos para 
el proceso neoplásico ${ }^{32}$. En este sentido y con el fin de conocer el rol de la metilación como mecanismo de inactivación de genes supresores de tumores y al mismo tiempo explorar su potencial uso como biomarcadores para el diagnóstico precoz del cáncer gástrico, nuestro grupo evaluó la metilación de la región promotora de 24 genes supresores de tumores que cubren las seis principales vías fisiológicas del cáncer ${ }^{39}$. El estudio se realizó en 136 casos retrospectivos ( 32 casos de tejido fresco y 104 casos de tejido incluidos en parafina). Adicionalmente incluimos 43 casos prospectivos coleccionados durante la ejecución de los proyectos. Nuestros resultados indicaron que la metilación de la región promotora de los genes BRCA1, p73, RARbeta, hMLH1, RIZI, RUNX3, MGMT y TIMP3 estaría asociado a una variante agresiva y emergente del cáncer gástrico difuso, el cáncer de células de anillo de sello ${ }^{40,41}$. Además, se determinó que la metilación del gen APC está asociada a mal pronóstico ${ }^{42}$ mientras que la metilación del gen BRCA1 parece estar asociada a casos de aparición temprana ${ }^{43}$. Sin embargo, debido a que nuestro interés en la identificación de biomarcadores incluía la posibilidad de usar muestras de tipo no invasivo, como suero o plasma, es que evaluamos siete genes (APC, SHP1, CDH1, ER, Reprimo, SEMA3B, 3OST2) que estaban frecuentemente metilados. Este análisis se realizó en casos prospectivos y de los cuales obtuvimos muestras pareadas de tejido tumoral y plasma. Estos casos se compararon con un grupo de controles sanos asintomáticos obtenidos a partir de dadores voluntarios de banco de sangre. Los resultados de este análisis se muestran en la Figura 2. En este análisis, se encontraron diferencias significativas en la metilación plasmática del gen Reprimo entre los pacientes con cáncer gástrico y controles asintomáticos. De manera específica,
Reprimo se encontró metilado en 96,8\% (41/43) y $83,3 \%$ (40/43) de las muestras de tumor y plasma de los casos de cáncer gástrico, respectivamente. En los controles asintomáticos, la metilación de Reprimo se encontró sólo en 9,7\% (31/33) de los casos analizados. Esta diferencia, muy significativa ( $\mathrm{p}<0,00001)$, sugeriría que habríamos identificado un biomarcador aplicable como prueba no invasiva para detección precoz de cáncer gástrico ${ }^{41}$.

\section{Reprimo y cáncer gástrico}

El gen Reprimo (símbolo oficial RPRM) se localiza en el cromosoma 2q23.3 $3^{43}$. Reprimo es inducido después de irradiación con rayos $\mathrm{X}$ de manera dependiente de p53, causando detención del ciclo celular en fase $\mathrm{G} 2^{45}$. Adicionalmente, la expresión ectópica de Reprimo también induce la detención G2, en donde se ha observado una inhibición tanto de la actividad de cdc2 como de la translocación nuclear de ciclina-B1. Estos antecedentes sugieren la participación de Reprimo en la vía de regulación del complejo cdc2/ciclina-B ${ }^{45}$. Análisis a nivel de ADN indican que RPRM sólo posee un exón de $393 \mathrm{pb}$, el cual codifica para una proteína de 109 aminoácidos. La región promotora de Reprimo contiene 56 dinucleótidos CpG en torno al sitio de inicio de transcripción (STT, start transcription site). Nuestro interés en evaluar la metilación de Reprimo como parte del panel de 24 genes, se originó en las publicaciones de Sato y $\mathrm{col}^{46}$ y Takahashi y $\mathrm{col}^{47}$. Sato y $\mathrm{col}^{46}$ realizaron análisis de microarrays en líneas celulares de cáncer de páncreas tratadas con la droga desmetilante 5-Aza-Citidina (5AzaC). Estos autores observaron que la re-expresión de Reprimo era altamente significativa en el post-tratamiento y validaciones

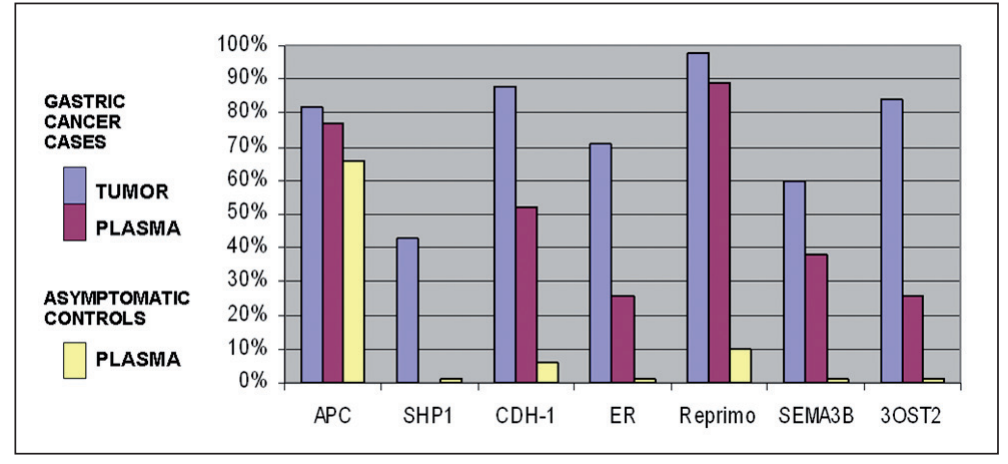

Figura 2. Resultados del análisis de metilación de ADN de la región promotora de sietes genes en 43 prospectivos de cáncer gástrico (tumor y plasma) y 31 controles sanos (dadores banco de sangre). Se observa que sólo Reprimo presenta frecuencias similares de metilación en tumor y plasma en los casos de cáncer gástrico y una significativa diferencia con controles sanos. Tomado de: Bernal et al., Clin Cancer Res 2008; 14: 6264-9. 
posteriores demostraron que Reprimo estaba metilado en 91\% (20/22) de líneas celulares y en 86\% (36/42) de muestras clínicas de cáncer de páncreas. Por otra parte y dado que la localización cromosómica de Reprimo es un sitio de alta inestabilidad en cáncer, Takahashi y $\mathrm{Col}^{47}$ realizaron un estudio del estado de metilación de Reprimo en 39 líneas celulares y en 645 muestras clínicas representativas de 16 tipos de tumores. Estos autores identificaron $82 \%$ de metilación en cáncer gástrico. En base a estos antecedentes, elegimos a Reprimo como uno de los 24 genes candidatos para evaluación como potencial biomarcador para la detección precoz de cáncer gástrico. Nuestros análisis en tejidos primarios nos permitió confirmar la alta frecuencia de metilación de Reprimo, ya descrita previamente $^{47}$. Sin embargo, nuestros análisis realizados en muestras pareadas de plasma nos permitieron extender esta observación a muestras no invasivas ${ }^{41}$. Inmediatamente posterior a nuestro hallazgo, el grupo de Correa y col. demostró que los niveles de Reprimo estaban significativamente más elevados en lesiones precursoras de cáncer gástrico (gastritis crónica y/o metaplasia intestinal) en poblaciones de alto riesgo ${ }^{48}$. Por otra parte, el mismo estudio demostró una asociación significativa entre la presencia de cepas "oncogénicas" de H. pylori, caracterizadas por poseer el gen cagA y los alelos s1m1 del gen VacA, y niveles elevados de Reprimo. Tomados en su conjunto, pareciera que Reprimo no sólo tendría características de potencial biomarcador para detección masiva de cáncer gástrico, sino que también podría cumplir un rol en la patogénesis de esta enfermedad. Ambas preguntas se encuentran en fase de evaluación a través de proyectos FONDAP y FONDECYT, respectivamente.

\section{Hipometilación del ADN y cáncer gástrico}

En los últimos años, otra alteración epigenética ha emergido como relevante en cáncer, la hipometilación del ADN. Aunque este mecanismo fue identificado hace más de 30 años $^{49}$, no fue considerado sino hasta hace poco tiempo atrás. En efecto, en varias publicaciones se ha redescubierto a la hipometilación como un mecanismo de activación de oncogenes $\mathrm{s}^{50-66}$. Estas publicaciones indican que la hipometilación de genes específicos, tales como $\mathrm{MAGE}^{51}$, synuclein-alfa ${ }^{52}, \mathrm{MUC2}{ }^{55}, \operatorname{maspin}^{57}$,
CAGE $^{56}$ y family A melanoma antigen ${ }^{61}$ ocurriría en las etapas avanzadas del cáncer. Finalmente, la sobreexpresión de reconocidos oncogenes como Myc, H-ras y ciclina D1 $1^{54,60}$ también ha sido asociada a la hipometilación de sus regiones promotoras. Tomado en conjunto, la hipometilación del ADN, en contraposición a la hipermetilación, sería un emergente mecanismo de activación de oncogenes en cáncer gástrico. En este sentido, y en un consecutivo proyecto, nuestro grupo evaluó a la hipometilación como mecanismo de activación de oncogenes en líneas celulares y muestras clínicas de cáncer gástrico. Habiendo identificado un potencial biomarcador a nivel no invasivo, el propósito de este nuevo proyecto fue identificar biomarcadores aplicables a muestras de biopsias para complementar la evaluación histológica de lesiones precursoras (gastritis crónica y/o metaplasia intestinal) con alto riesgo de progresar a cáncer gástrico. En particular, es conocido el riesgo de progresión a cáncer de lesiones intramucosas o displasia gástrica ${ }^{67}$. Sin embargo, el riesgo de progresión de lesiones precursoras (gastritis crónica y/o metaplasia intestinal) no es tan claro ${ }^{68,69}$. En este escenario y como producto de un estudio bioinformático, en el que analizamos la sobreexpresión de genes regulados por hipometilación en bases de datos de dominio público ${ }^{70}$, logramos identificar 38 genes candidatos, entre los cuales emergieron genes reconocidos previamente, como la proteína tumoral p73, miembro de la familia de p53 con una función dual oncogén/gen supresor de tumores en cáncer. En una serie de casos de gastritis y cáncer gástrico $(\mathrm{n}=15)$ y realizando microdisección de células epiteliales, observamos una correlación inversa entre metilación y expresión. Esta información fue concordante con el concepto de activación oncogénica mediada por hipometilación. A continuación analizamos el perfil de sobreexpresión de p73 y otros genes (BRCA1, HSP90, STAT1, FHIT, EGFR, p53, p16INK4a) asociados a activación por hipometilación ${ }^{71-79}$ en microarreglos de tejidos (TMA, tissue microarray) de cáncer gástrico (mucosa gástrica tumoral y mucosa adyacente al tumor, $n=91)$ y gastritis $(n=148)$. En forma paralela a este análisis evaluamos las características histológicas de los casos según el sistema de Sydney para gastritis crónica y OLGA (Operative Link on Gastritis Assessment) para la evaluación de atrofia ${ }^{80,81}$. El análisis histológico nos permitió identificar atrofia y metaplasia intestinal severa 


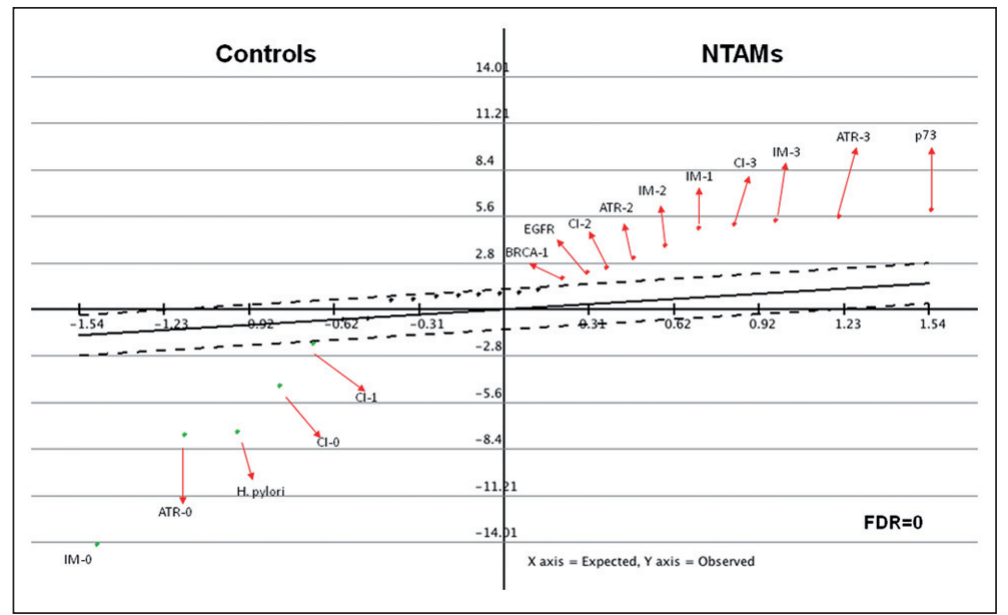

Figura 3. Análisis de SAM (Serial Analysis por Microarray) para la integración de variables histológicas e inmunohistoquímicas en gastritis crónica y mucosa no tumoral de cáncer gástrico incipiente. La combinación de parámetros histológicos e inmunohistoquímicos permite identificar a p73, como la variable de mayor riesgo de progresión de gastritis crónica a cáncer gástrico. Tomado de Carrasco et al., Clin Cancer Res, 2010: 16: 3253-9. en la mayoría de las mucosas adyacentes a tumor en comparación con los casos de gastritis. En las mismas mucosas adyacentes se observó una significativa mayor sobreexpresión de p73. Finalmente, la combinación de los parámetros histológicos e inmunohistoquímicos nos permitió identificar la sobreexpresión de p73, atrofia severa y OLGA - IV como los parámetros más significativos de lesiones precursoras con alto riesgo de progresar a cáncer gástrico (Figura 3).

\section{Conclusiones finales}

Tomados en conjunto, la información presentada ha permitido delinear el rol de la epigenética en las bases moleculares del cáncer gástrico con énfasis en el desarrollo de biomarcadores para uso clínico y/o poblacional. En este sentido, uno de los genes identificados, Reprimo, inactivado por hipermetilación, sería un potencial biomarcador no invasivo para la detección masiva del cáncer gástrico. Por otra parte, la activación de p73 por hipometilación sería un biomarcador para evaluar el riesgo de lesiones precursoras de progresar a cáncer gástrico. Los hallazgos presentados indican un importante rol de la epigenética, en particular la híper o hipometilación del ADN, en la patogénesis del cáncer gástrico.

\section{Referencias}

1. Ferlay J, Shin HR, Bray F, Forman D, Mathers C, Parkin DM. Estimates of worldwide burden of cancer in 2008:
GLOBOCAN 2008. Int J Cancer 2010; 127 (12): 2893 917.

2. Heise K, Bertran E, Andia ME, Ferreccio C. Incidence and survival of stomach cancer in a high-risk population of Chile. World J Gastroenterol 2009; 15 (15): 1854-62.

3. de Vries AC, van Grieken NC, Looman CW, Casparie MK, de Vries E, Meijer GA, et al. Gastric cancer risk in patients with premalignant gastric lesions: a nationwide cohort study in the Netherlands. Gastroenterology 2008; 134 (4): 945-52.

4. Garrido M, Melgoza G, Galindo H, Madrid J, Sánchez C, Nervi B, et al. [Treatment of advanced gastric cancer with oxaliplatin plus 5-fluorouracil/ leucovorin (FOLFOX-4 chemotherapy)]. Rev Med Chile 2007; 135 (11): 1380-7.

5. Anderson WF, Camargo MC, Fraumeni JF, Jr. Correa P, Rosenberg PS, Rabkin CS. Age-specific trends in incidence of noncardia gastric cancer in US adults. JAMA 2010; 303 (17): 1723-8.

6. Mathers CD, Loncar D. Projections of global mortality and burden of disease from 2002 to 2030. PLoS Med 2006; 3 (11): e442.

7. Songun I, van de Velde CJ, Arends JW, Blok P, Grond AJ, Offerhaus GJ, et al. Classification of gastric carcinoma using the Goseki system provides prognostic information additional to TNM staging. Cancer 1999; 85 (10): 2114-8.

8. Borchard F. Classification of gastric carcinoma. Hepatogastroenterology 1990; 37 (2): 223-32.

9. Goseki N, Takizawa T, Koike M. Differences in the mode of the extension of gastric cancer classified by histological type: new histological classification of gastric carcinoma. Gut 1992; 33 (5): 606-12. 
10. Mulligan RM. Histogenesis and biologic behavior of gastric carcinoma. Pathol Annu 1972; 7: 349-415.

11. Ming SC. Gastric carcinoma. A pathobiological classification. Cancer 1977; 39 (6): 2475-85.

12. Jass JR, Sobin LH, Watanabe H. The World Health Organization's histologic classification of gastrointestinal tumors. A commentary on the second edition. Cancer 1990; 66 (10): 2162-7.

13. Lauren P. The Two Histological Main Types of Gastric Carcinoma: Diffuse and So-Called Intestinal-Type Carcinoma. An Attempt at a Histo-Clinical Classification. Acta Pathol Microbiol Scand 1965; 64: 31-49.

14. Correa P, Haenszel W, Cuello C, Tannenbaum S, Archer MA. Model for gastric cancer epidemiology. Lancet 1975; 2 (7924): 58-60.

15. Correa P, Houghton J. Carcinogenesis of Helicobacter pylori. Gastroenterology 2007; 133 (2): 659-72.

16. Fenoglio-Preiser C, Carneiro F, Correa P, Guilford P, Lambert B, Megraud F, et al. Gastric Carcinoma. In: Hamilton HB, Aaltonen L, eds. Pathology and Genetics of Tumours of the Digestive System. Lyon: IARC Press, 2000; 37-68.

17. Correa PA. Human model of gastric carcinogenesis. Cancer Res 1988; 48 (13): 3554-60.

18. Kim JH, Takahashi T, Chiba I, Park JG, Birrer MJ, Roh $\mathrm{JK}$, et al. Occurrence of $\mathrm{p} 53$ gene abnormalities in gastric carcinoma tumors and cell lines. J Natl Cancer Inst 1991; 83 (13): 938-43.

19. Falck VG, Gullick WJ. c-erbB-2 oncogene product staining in gastric adenocarcinoma. An immunohistochemical study. J Pathol 1989; 159 (2): 107-11.

20. Yonemura Y, Ninomiya I, Yamaguchi A, Fushida S, Kimura H, Ohoyama S, et al. Evaluation of immunoreactivity for erbB-2 protein as a marker of poor short term prognosis in gastric cancer. Cancer Res 1991; 51 (3): 1034-8.

21. Yonemura Y, Ninomiya I, Ohoyama S, Kimura H, Yamaguchi A, Fushida S, et al. Expression of c-erbB-2 oncoprotein in gastric carcinoma. Immunoreactivity for c-erbB-2 protein is an independent indicator of poor short-term prognosis in patients with gastric carcinoma. Cancer 1991; 67 (11): 2914-8.

22. Corvalán A. Bases Moleculares del Cáncer Gástrico. In: Csendes A, Korn O, Burdiles P, eds. Cáncer Gástrico. Santiago: Editorial Mediterráneo 2006; 27-35.

23. Carneiro F, Oliveira C, Leite M, Seruca R. Molecular targets and biological modifiers in gastric cancer. Semin Diagn Pathol 2008; 25 (4): 274-87.

24. Carrasco G, Díaz J, Valbuena JR, Ibáñez P, Rodríguez P, Araya G, et al. Overexpression of p 73 as a tissue marker for high-risk gastritis. Clin Cancer Res 2010; 16 (12): 3253-9.
25. Guilford P, Hopkins J, Harraway J, McLeod M, McLeod $\mathrm{N}$, Harawira $\mathrm{P}$, et al. E-cadherin germline mutations in familial gastric cancer. Nature 1998; 392 (6674): 402-5.

26. Dunbier A, Guilford P. Hereditary diffuse gastric cancer. Adv Cancer Res 2001; 83: 55-65.

27. Guilford P, Humar B, Blair V. Hereditary diffuse gastric cancer: translation of $\mathrm{CDH} 1$ germline mutations into clinical practice. Gastric Cancer 2010; 13 (1): 1-10.

28. Oliveira C, Seruca R, Carneiro F. Hereditary gastric cancer. Best Pract Res Clin Gastroenterol 2009; 23 (2): 147-57.

29. Becker KF, Atkinson MJ, Reich U, Becker I, Nekarda H, Siewert JR, et al. E-cadherin gene mutations provide clues to diffuse type gastric carcinomas. Cancer Res 1994; 54 (14): 3845-52.

30. Ascano JJ, Frierson H, Jr. Moskaluk CA, Harper JC, Roviello F, Jackson CE, et al. Inactivation of the E-cadherin gene in sporadic diffuse-type gastric cancer. Mod Pathol 2001; 14 (10): 942-9.

31. Semba S, Yokozaki H, Yasui W, Tahara E. Frequent microsatellite instability and loss of heterozygosity in the region including BRCA1 (17q21) in young patients with gastric cancer. Int J Oncol 1998; 12 (6): 1245-51.

32. Tamura G. Alterations of tumor suppressor and tumorrelated genes in the development and progression of gastric cancer. World J Gastroenterol 2006; 12 (2): 192-8.

33. Jankowski JA, Odze RD. Biomarkers in gastroenterology: between hope and hype comes histopathology. Am J Gastroenterol 2009; 104 (5): 1093-6.

34. Riggs AD, Russo VEA, Martienssen RA (1996). Epigenetic mechanisms of gene regulation. Plainview, N.Y: Cold Spring Harbor Laboratory Press. ISBN 0-87969-490-4.

35. Corvalán AH. Early Diagnosis of Hepatocellular Carcinoma by MicroRNAs: Shining a Light from the Genome's "Dark Matter". Dig Dis Sci 2012. Sep 28. [Epub ahead of print].

36. Chen ZX, Riggs AD. DNA methylation and demethylation in mammals. J Biol Chem 2011; 286 (21): 18347-53.

37. Tsai HC, Baylin SB. Cancer epigenetics: linking basic biology to clinical medicine. Cell Res 2011; 21 (3): 50217.

38. Fleisher AS, Esteller M, Wang S, Tamura G, Suzuki $\mathrm{H}$, Yin J, et al. Hypermethylation of the hMLH1 gene promoter in human gastric cancers with microsatellite instability. Cancer Res 1999; 59 (5): 1090-5.

39. Hanahan D, Weinberg RA. Hallmarks of cancer: the next generation. Cell 2011; 144 (5): 646-74.

40. Henson DE, Dittus C, Younes M, Nguyen H, AlboresSaavedra J. Differential trends in the intestinal and diffuse types of gastric carcinoma in the United States, 
1973-2000: increase in the signet ring cell type. Arch Pathol Lab Med 2004; 128 (7): 765-70.

41. Bernal C, Aguayo F, Villarroel C, Vargas M, Díaz I, Ossandón FJ, et al. Reprimo as a potential biomarker for early detection in gastric cancer. Clin Cancer Res 2008; 14 (19): 6264-9.

42. Zavala GL, Luengo JV, Ossandón CF, Riquelme SE, Backhouse EC, Palma VM, et al. [Hierarchical clustering analysis to detect associations between clinical and pathological features of gastric tumors and hypermethylation of suppressor genes]. Rev Med Chile 2007; 135 (1): 17-25.

43. Bernal C, Vargas M, Ossandón F, Santibáñez E, Urrutia J, Luengo $\mathrm{V}$, et al. DNA methylation profile in diffuse type gastric cancer: evidence for hypermethylation of the BRCA1 promoter region in early-onset gastric carcinogenesis. Biol Res 2008; 41 (3): 303-15.

44. Corvalán AH, Torres V. RPRM (reprimo, TP53 dependent G2 arrest mediator candidate). Atlas Genet Cytogenet Oncol Haematol. 2011(November).

45. Ohki R, Nemoto J, Murasawa H, Oda E, Inazawa J, Tanaka N, et al. Reprimo, a new candidate mediator of the p53-mediated cell cycle arrest at the G2 phase. J Biol Chem 2000; 275 (30): 22627-30.

46. Sato N, Fukushima N, Maitra A, Matsubayashi H, Yeo CJ, Cameron JL, et al. Discovery of novel targets for aberrant methylation in pancreatic carcinoma using high-throughput microarrays. Cancer Res 2003; 63 (13): 3735-42.

47. Takahashi T, Suzuki M, Shigematsu H, Shivapurkar N, Echebiri C, Nomura M, et al. Aberrant methylation of Reprimo in human malignancies. Int J Cancer 2005; 115 (4): 503-10.

48. Schneider BG, Peng DF, Camargo MC, Piazuelo MB, Sicinschi LA, Mera R, et al. Promoter DNA hypermethylation in gastric biopsies from subjects at high and low risk for gastric cancer. Int J Cancer 2010; 127 (11): 2588-97.

49. Christman JK, Price P, Pedrinan L, Acs G. Correlation between hypomethylation of DNA and expression of globin genes in Friend erythroleukemia cells. Eur J Biochem 1977; 81 (1): 53-61.

50. Cravo M, Pinto R, Fidalgo P, Chaves P, Gloria L, NobreLeitao C, et al. Global DNA hypomethylation occurs in the early stages of intestinal type gastric carcinoma. Gut 1996; 39 (3): 434-8.

51. Honda T, Tamura G, Waki T, Kawata S, Terashima M, Nishizuka S, et al. Demethylation of MAGE promoters during gastric cancer progression. Br J Cancer 2004; 90 (4): 838-43.

52. Yanagawa N, Tamura G, Honda T, Endoh M, Nishizuka
S, Motoyama T. Demethylation of the synuclein gamma gene $\mathrm{CpG}$ island in primary gastric cancers and gastric cancer cell lines. Clin Cancer Res 2004; 10 (7): 2447-51.

53. Ichinose M, Miki K, Tatematsu M, Mizuno T, Mutai M, Furihata C, et al. Cell-specific hypomethylation of the pepsinogen gene in pepsinogen-producing cells. Biochem Biophys Res Commun 1988; 155 (2): 670-7.

54. Fang JY, Zhu SS, Xiao SD, Jiang SJ, Shi Y, Chen XY, et al. Studies on the hypomethylation of c-myc, c-Ha-ras oncogenes and histopathological changes in human gastric carcinoma. J Gastroenterol Hepatol 1996; 11 (11): 1079-82.

55. Mesquita P, Peixoto AJ, Seruca R, Hanski C, Almeida R, Silva F, et al. Role of site-specific promoter hypomethylation in aberrant MUC2 mucin expression in mucinous gastric carcinomas. Cancer Lett 2003; 189 (2): 129-36.

56. Cho B, Lee H, Jeong S, Bang YJ, Lee HJ, Hwang KS, et al. Promoter hypomethylation of a novel cancer/ testis antigen gene CAGE is correlated with its aberrant expression and is seen in premalignant stage of gastric carcinoma. Biochem Biophys Res Commun 2003; 307 (1): 52-63

57. Akiyama Y, Maesawa C, Ogasawara S, Terashima M, Masuda T. Cell-type-specific repression of the maspin gene is disrupted frequently by demethylation at the promoter region in gastric intestinal metaplasia and cancer cells. Am J Pathol 2003; 163 (5): 1911-9.

58. Oshimo Y, Nakayama H, Ito R, Kitadai Y, Yoshida K, Chayama K, et al. Promoter methylation of cyclin D2 gene in gastric carcinoma. Int J Oncol 2003; 23 (6): 1663-70.

59. Kaneda A, Tsukamoto T, Takamura-Enya T, Watanabe N, Kaminishi M, Sugimura T, et al. Frequent hypomethylation in multiple promoter $\mathrm{CpG}$ islands is associated with global hypomethylation, but not with frequent promoter hypermethylation. Cancer Sci 2004; 95 (1): 58-64.

60. Chalitchagorn K, Shuangshoti S, Hourpai N, Kongruttanachok N, Tangkijvanich $\mathrm{P}$, Thong-ngam D, et al. Distinctive pattern of LINE-1 methylation level in normal tissues and the association with carcinogenesis. Oncogene 2004; 23 (54): 8841-6.

61. Jung EJ, Kim MA, Lee HS, Yang HK, Lee YM, Lee BL, et al. Expression of family A melanoma antigen in human gastric carcinoma. Anticancer Res 2005; 25 (3B): 210511.

62. Nishigaki M, Aoyagi K, Danjoh I, Fukaya M, Yanagihara K, Sakamoto H, et al. Discovery of aberrant expression of R-RAS by cancer-linked DNA hypomethylation in gastric cancer using microarrays. Cancer Res 2005; 65 (6): 2115-24.

63. Goelz SE, Vogelstein B, Hamilton SR, Feinberg AP. 
Hypomethylation of DNA from benign and malignant human colon neoplasms. Science 1985; 228 (4696): 18790.

64. Narayan A, Ji W, Zhang XY, Marrogi A, Graff JR, Baylin $\mathrm{SB}$, et al. Hypomethylation of pericentromeric DNA in breast adenocarcinomas. Int J Cancer 1998; 77 (6): 8338.

65. Lin CH, Hsieh SY, Sheen IS, Lee WC, Chen TC, Shyu WC, et al. Genome-wide hypomethylation in hepatocellular carcinogenesis. Cancer Res 2001; 61 (10): 4238-43.

66. Bariol C, Suter C, Cheong K, Ku SL, Meagher A, Hawkins $\mathrm{N}$, et al. The relationship between hypomethylation and $\mathrm{CpG}$ island methylation in colorectal neoplasia. Am J Pathol 2003; 162 (4): 1361-71.

67. Rugge M, Correa P, Dixon MF, Hattori T, Leandro G, Lewin K, et al. Gastric dysplasia: the Padova international classification. Am J Surg Pathol 2000; 24 (2): 167-76.

68. Tan YK, Fielding JW. Early diagnosis of early gastric cancer. Eur J Gastroenterol Hepatol 2006; 18 (8): 821-9.

69. Vieth M, Stolte M. Elevated risk for gastric adenocarcinoma can be predicted from histomorphology. World J Gastroenterol 2006; 12 (38): 6109-14.

70. Ossandón FJ, Villarroel C, Aguayo F, Santibáñez E, Oue $\mathrm{N}$, Yasui W, et al. In silico analysis of gastric carcinoma Serial Analysis of Gene Expression libraries reveals different profiles associated with ethnicity. Mol Cancer 2008; 7: 22.

71. Szaumkessel M, Richter J, Giefing M, Jarmuz M, Kiwerska K, Tonnies $\mathrm{H}$, et al. Pyrosequencing-based DNA methylation profiling of Fanconi anemia/BRCA pathway genes in laryngeal squamous cell carcinoma. Int J Oncol 2011; 39 (2): 505-14.

72. Daskalos A, Logotheti S, Markopoulou S, Xinarianos G, Gosney JR, Kastania AN, et al. Global DNA hypomethylation-induced DeltaNp73 transcriptional activation in non-small cell lung cancer. Cancer Lett 2011; 300 (1): 79-86.

73. Nien WL, Dauphinee SM, Moffat LD, Too CK. Overexpression of the mTOR alpha4 phosphoprotein activates protein phosphatase 2A and increases Statlalpha bin- ding to PIAS1. Mol Cell Endocrinol 2007; 263 (1-2): 10-7.

74. Rusiecki JA, Al-Nabhani M, Tarantini L, Chen L, Baccarelli A, Al-Moundhri MS. Global DNA methylation and tumor suppressor gene promoter methylation and gastric cancer risk in an Omani Arab population. Epigenomics 2011; 3 (4): 417-29.

75. Shutoh Y, Takeda M, Ohtsuka R, Haishima A, Yamaguchi $\mathrm{S}$, Fujie H, et al. Low dose effects of dichlorodiphenyltrichloroethane (DDT) on gene transcription and DNA methylation in the hypothalamus of young male rats: implication of hormesis-like effects. J Toxicol Sci 2009; 34 (5): 469-82.

76. Tanaka H, Shimada Y, Harada H, Shinoda M, Hatooka S, Imamura M, et al. Methylation of the 5' CpG island of the FHIT gene is closely associated with transcriptional inactivation in esophageal squamous cell carcinomas. Cancer Res 1998; 58 (15): 3429-34.

77. Valdez BC, Li Y, Murray D, Corn P, Champlin RE, Andersson BS. 5-Aza-2'-deoxycytidine sensitizes busulfanresistant myeloid leukemia cells by regulating expression of genes involved in cell cycle checkpoint and apoptosis. Leuk Res 2010; 34 (3): 364-72.

78. Yu Y, Kanwar SS, Patel BB, Nautiyal J, Sarkar FH, Majumdar AP. Elimination of Colon Cancer Stem-Like Cells by the Combination of Curcumin and FOLFOX. Transl Oncol 2009; 2 (4): 321-8.

79. Fornari F, Milazzo M, Chieco P, Negrini M, Marasco E, Capranico G, et al. In hepatocellular carcinoma miR519d is up-regulated by 553 and DNA hypomethylation and targets CDKN1A/p21, PTEN, AKT3 and TIMP2. J Pathol 2012; 227 (3): 275-85.

80. Dixon MF, Genta RM, Yardley JH, Correa P. Classification and grading of gastritis. The updated Sydney System. International Workshop on the Histopathology of Gastritis, Houston 1994. Am J Surg Pathol 1996; 20 (10): 1161-81.

81. Rugge M, Pennelli G, Pilozzi E, Fassan M, Ingravallo G, Russo VM, et al. Gastritis: the histology report. Dig Liver Dis 2011; 43 Suppl 4: S373-84. 